Petr Jonsta - Irena Vlckova - Zdenek Jonsta - Vladimir Tomasek - Tatana Fenclova*

\title{
RESISTANCE OF HIGH-STRENGTH STEELS TO STRESS CORROSION CRACKING DEPENDING ON EXTERNAL ENVIRONMENT PH FACTOR
}

The paper deals with the study of stress corrosion cracking of high-strength steels in an aqueous environment with a varying $p H$ factor ranging from 5.5 to 12.0. Steels were studied after quenching and tempering, one of the steels was prone to temper embrittlement.

Single-edge notched pre-cracked specimens were used for the experiments. Changes in the $p H$ factor at the crack tip were measured using an antimony electrode. The $\mathrm{pH}$ factor values at the crack tip dropped to 2.0. Steel prone to temper embrittlement showed significantly shorter incubation period and more accelerated development of corrosion process compared to the optimized heat treatment of the second steel. Proneness to intergranular fracture was observed close to the fatigue crack tip. The obtained results expand the existing knowledge about localized corrosion processes leading to the refinement of the stress corrosion cracking model when changing the $\mathrm{pH}$ factor on the crack tip.

Keywords: high-strength steels, heat treatment, stress corrosion cracking, pH factor, intergranular fracture

\section{Introduction}

Steel structures are often multi-axially stressed and may be damaged by a different degradation mechanisms which cause to a loss of stability, excessive corrosion, corrosion fatigue etc. High-strength steels are materials with a higher yield and tensile strength which allows to use a structures with a lower weight. Due to that fact, the high-strength steels are used in many transportations applications. High stability of mechanical properties at high strain rate is used in automotive industry (crash-testing of vehicle). Mining and military industry offers the possibility of further applications, e.g. loaders, excavators, armored transporters etc.

Stress corrosion cracking (SCC) is one of the predominant failures of high-strength steels. The SCC is characterized by initiation and stable crack growth rate due to the simultaneous effect of tensile stress and long-term exploitation in aqueous environment. Initiation and stable crack growth rate, due to the SCC, occur when environmental characteristics, stress state and material properties simultaneously reach certain critical levels [1], [2]. The stable crack growth rate is characterized by the presence of the stress intensity factor threshold value $\left(\mathrm{K}_{\mathrm{ISCC}}\right.$. Shipilov [3] argued that the SCC is a special case of the corrosion fatigue.

The SCC is affected by a number of factors that can be divided into three groups. The stress mode, especially the stress state at critical points of the steel construction (static or cyclic tensile stress, residual stress), strain rate and frequency of cycling are included into the first group.

The second group involves properties of aqueous environment and temperature regime and the third group involves metallurgical factors (chemical composition, microstructure), the yield stress and heat treatment.

The SCC is related to electrochemical reactions, especially to changes in the $p H$ factor at the tip of the growing crack, as Hirth states [4]. Two types of the SCC, which are often differentiated as the high $p H$ or intergranular SCC (IGSCC) and the near-neutral $p H$ or transgranular SCC (TGSCC) have been identified in works [5], [6], [7], [8].

The mechanism of the IGSCC is attributed to anodic dissolution resulting from selective dissolution at the grain boundaries and repeated rupture of passivate films that form over the crack tip [9].

The increase of deformation at the crack tip needed to rupture the oxidation layer may be caused by the monotonically increasing load, respectively by the creep at the constant load. When the oxidation layer is ruptured, the crack tip is exposed. Subsequently, the crack is affected by an aqueous environment with aggression depending on concentration of anions at the crack tip.

Aggression of environment at the crack tip is increasing by dissolution of the $\mathrm{MnS}$ inclusions and/or by gradient of potential between mouth and tip of the crack. Gradient of potential depends on oxygen concentration, which is dissoluted in water. A crack tip grows as a result of anodic dissolution. Simultaneously, the crack tip is progressively covered by the increasing passivation layer and the crack growth slows down.

In case of the TGSCC, great efforts have been made to understand the fundamental role of hydrogen and its synergism with stress in a few last years, as presented in works [10], [11]. The stable crack growth rate is controlled by successive partial processes, which included transport of corrosive environment

\footnotetext{
* ${ }^{1}$ Petr Jonsta, ${ }^{2}$ Irena Vlckova, ${ }^{1}$ Zdenek Jonsta, ${ }^{1}$ Vladimir Tomasek, ${ }^{1}$ Tatana Fenclova ${ }^{1}$ Faculty of Metallurgy and Materials Engineering, VSB-TU Ostrava, Czech Republic ${ }^{2}$ RMTSC, Material \& Metallurgical Research Ltd., Remote Site Ostrava, VUHZ a.s., Dobra, Czech Republic E-mail: petr.jonsta@vsb.cz
} 
Table 1 The chemical composition of the steels (wt. \%)

\begin{tabular}{ccccccccccc}
\hline Steel & $\mathrm{C}$ & $\mathrm{Mn}$ & $\mathrm{Si}$ & $\mathrm{Cr}$ & $\mathrm{Ni}$ & $\mathrm{Mo}$ & $\mathrm{P}$ & 0.013 & 0.009 \\
Mn-Si-Mo & 0.30 & 1.42 & 1.38 & 0.22 & 0.36 & 1.82 & 0.32 & 0.012 \\
30Cr2Ni2Mo & 0.32 & 0.55 & 0.32 & 1.95 & 0.010 \\
\hline
\end{tabular}

Table 2 Mechanical properties of the steels

\begin{tabular}{ccccc}
\hline Steel & $\begin{array}{c}\text { Yield Strength } \\
0.2 \% \text { offset } \\
(\mathrm{MPa})\end{array}$ & $\begin{array}{c}\text { Tensile Strength } \\
(\mathrm{MPa})\end{array}$ & $\begin{array}{c}\text { Elongation } \\
\text { in } 50 \mathrm{~mm} \\
(\%)\end{array}$ & $\begin{array}{c}\text { Reduction } \\
\text { of Area } \\
(\%)\end{array}$ \\
\hline Mn-Si-Mo & 1490 & 1720 & 12 & $\begin{array}{c}\text { Notch } \\
\text { Toughness } \\
\left(\mathrm{J} \cdot \mathrm{cm}^{-2}\right)\end{array}$ \\
$30 \mathrm{Cr} 2 \mathrm{Ni2Mo}$ & 1600 & 1762 & 12 & 56 \\
\hline
\end{tabular}

into the crack tip, electrochemical reactions of the corrosive environment with newly created surfaces causing release of hydrogen, absorption of hydrogen at the crack tip, transport of hydrogen to areas where it is causing the embrittlement, the hydrogen-metal interaction that leads to embrittlement (reduced cohesive strength of grain boundaries, affecting mobility of dislocations, etc.). The resulting crack growth rate is then controlled by the slowest of the above processes.

The evaluation of structural metallurgical characteristics of the SCC has shown that in high-strength steels with a structure of martensite tempered at low temperatures there is a preferential occurrence of intergranular fracture when exposed to an aqueous environment [1], [4]. It is debatable whether this occurrence can be influenced by the heat treatment in a mentioned fracture mechanism, in other words, how the microstructure of low-tempered martensite contributes to the fracture development during the SCC in an aqueous solution.

The presented paper is focused on the SCC of two highstrength steels used in nuclear and classical power engineering. Steels were studied after quenching and tempering, one of the steels was prone to temper embrittlement. The aim of the work was to study the influence corrosion environment near the crack tip, in order to strengthen the knowledge about the mechanisms of the SCC processes of high-strength steels. In this context, attention was primarily focused on the study of changes in the $p H$ factor of the solution near the crack tip during the, corrosion tests with a different $p H$ baseline.

\section{Materials and experimental procedure}

Thermo-mechanically treated $14 \mathrm{~mm}$ thick sheets made of Mn-Si-Mo and 30Cr2Ni2Mo high-strength steels were used. Final rolled sheets were quenched and tempered by regime:

- $850{ }^{\circ} \mathrm{C} /$ water $+260{ }^{\circ} \mathrm{C} / 4 \mathrm{~h} /$ air (Mn-Si-Mo steel)

- $880^{\circ} \mathrm{C} /$ water $+250{ }^{\circ} \mathrm{C} / 4 \mathrm{~h} /$ air (30Cr2Ni2Mo steel)

The chemical composition of the steels is given in Table 1 .

Structural analysis was performed by optical metallography and scanning electron microscopy (SEM). The tensile properties were determined using an MTS $100 \mathrm{kN}$ machine on flat specimens, which were taken from the mid-thickness of the materials in the longitudinal direction. The notch toughness was measured on the standard Charpy impact specimens at ambient temperature. The mechanical properties of the steels are summarized in Table 2.

The SCC susceptibility measurements were determined using the creep machines on single-edge notched pre-cracked specimens which were $10 \mathrm{~mm}$ thick and $25 \mathrm{~mm}$ width. An angle of notch was $\alpha=$ $45^{\circ}$. A fatigue crack of approx. $2 \mathrm{~mm}$ in length was initiated at the root of the notch. Crack opening was determined by an inductive sensor and automatically registered. The specimen was placed in a specific plastic and organic glass cell.

The SCC tests were performed in distilled water and in an aqueous solution of $3.5 \% \mathrm{NaCl}$ solution. Tests were carried out at $p H=6$ baseline value and after addition of $1 \mathrm{M}$ of $\mathrm{NaOH}$ solution at $p H=12$. Antimony electrodes of the authors' own design, with a wide range of applications, were used to measure the $p H$ factor in the crack. For each measurement, 5 pairs of electrodes were used. The function of the electrodes has been verified by long-term measurements together with commercially saturated calomel electrodes. Both electrodes were placed in the holder together due to ensuring a constant distance during measurement a calibration.

In the SCC tests, the ratio of $\mathrm{Fe}^{2+} / \mathrm{Fe}^{3+}$ concentrations, at different crack and notch points, was also measured by measuring the oxidation-reduction potential. In this case, the antimony electrodes were replaced by platinum.

\section{Results and discussion}

The microstructure of the Mn-Si-Mo steel after the heat treatment was formed by a mixture of lath and partially plate martensite, containing approx. $3 \%$ retained austenite. The microstructure is presented in Figure 1.

The $30 \mathrm{Cr} 2 \mathrm{Ni} 2 \mathrm{Mo}$ steel, after the heat treatment, was also characterized by a microstructure of lath and plate martensite with a retained austenite content of 5-6\%. Because of the low Si content, tempering of the martensitic structure caused the low-temperature temper embrittlement. The embrittlement is characterized by the preferential etching of the original austenitic grains after etching in aqueous picric acid solution and surfactant, as shown in Figure 2.

The overall results of the $p H$ factor changes in the Mn-Si-Mo steel, at their different baselines, are presented in Table 3. For further details on ongoing changes in the $p H$ factor baseline, this table also provides data on $p H$ factor values in the solution volume. 


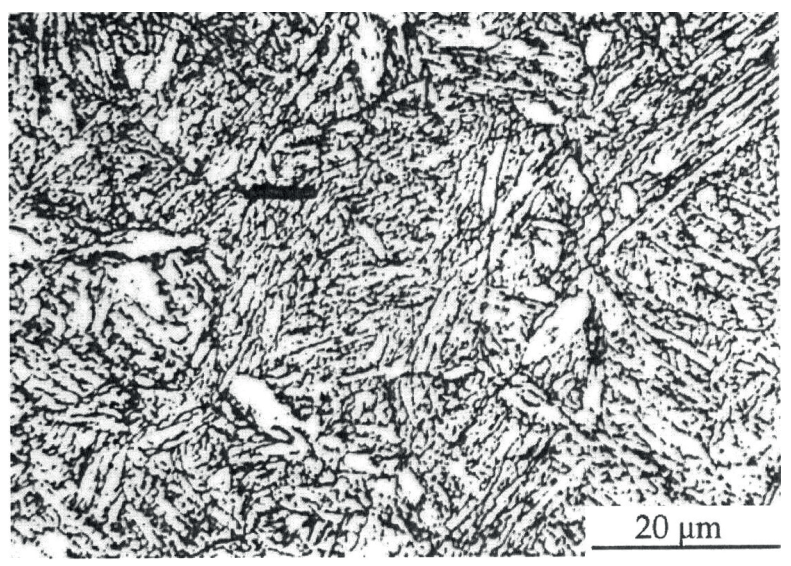

Figure 1 Microstructure of the Mn-Si-Mo steel (mixture of lath and partially plate martensite, containing approx. $3 \%$ retained austenite)

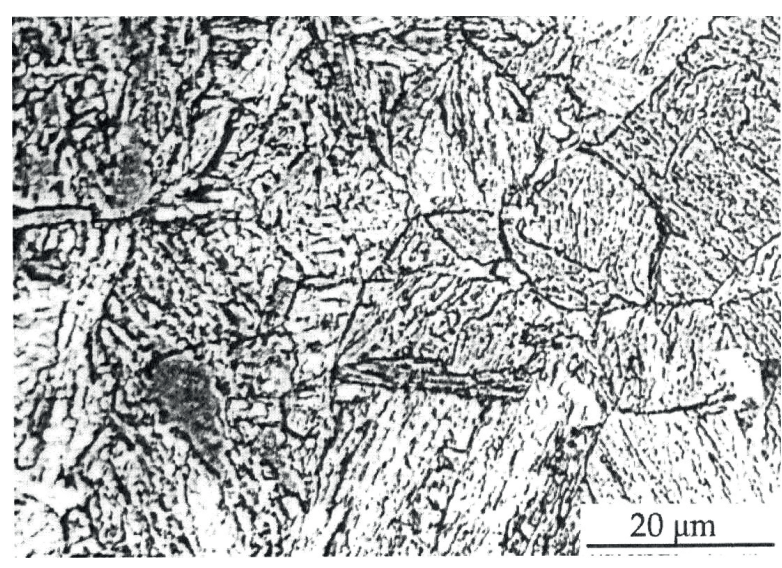

Figure 2 Microstructure of the 30Cr2Ni2Mo steel (lath and plate martensite with a retained austenite content of 5-6\%)

Table $3 \mathrm{pH}$ values of stress corrosion cracking test

\begin{tabular}{|c|c|c|c|c|c|c|}
\hline \multirow{2}{*}{$\begin{array}{c}\text { Corrosion } \\
\text { solution }\end{array}$} & \multicolumn{2}{|c|}{ Volume } & \multicolumn{2}{|c|}{ Crack tip } & \multicolumn{2}{|c|}{ Notch mouth } \\
\hline & $p H_{\text {start }}$ & $p H_{\text {finish }}$ & $p H_{\min }$ & $t(\min )$ & $p H_{\max }$ & $t(\min )$ \\
\hline $3.5 \% \mathrm{NaCl}$ & 6.54 & 6.32 & 2.7 & 20 & 12.0 & 400 \\
\hline \multirow[t]{2}{*}{ neutral } & 6.07 & 6.37 & 2.9 & 20 & 9.5 & $220-350$ \\
\hline & 6.40 & 7.43 & 1.5 & - & 9.5 & - \\
\hline $3.5 \% \mathrm{NaCl}$ & 12.07 & 11.17 & 3.6 & $1500-1800$ & 13.5 & 320 \\
\hline \multirow[t]{2}{*}{ alkaline } & 12.16 & 11.20 & 1.9 & $350-650$ & 13.1 & 200 \\
\hline & 11.40 & - & 1.5 & $0-50$ & - & - \\
\hline distilled water & 5.50 & 6.05 & 2.8 & $1600-2200$ & 7.5 & 200 \\
\hline alkaline water & 12.15 & 13.13 & 1.2 & 3300 & 12.7 & - \\
\hline
\end{tabular}

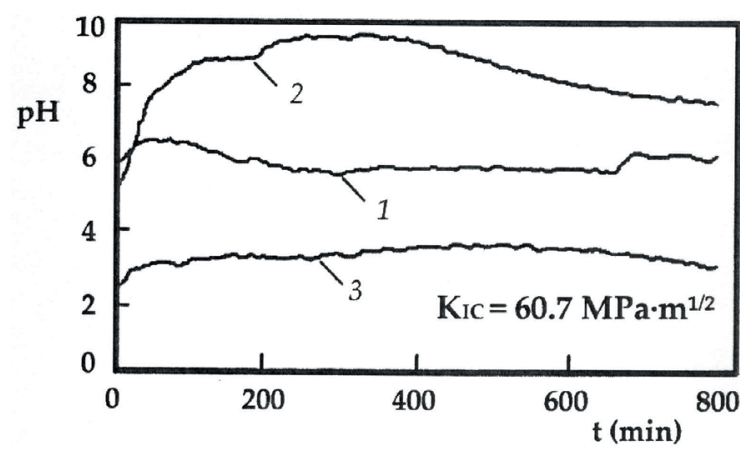

Figure 3 Time flow of measured values of the $\mathrm{pH}$ factor for baseline $\mathrm{pH}=6$

The timelines of measured $\mathrm{pH}$ values during the corrosion cracking tests in $3.5 \%$ aqueous, neutral and alkalized $\mathrm{NaCl}$ solutions, are presented in Figure 3 and Figure 4 for both baselines $p H=6$ and $p H=12$.

Curve 1 represents the measured values of the $p H$ factor changes determined at the top of the notch, curve 2 at the notch mouth and the curve 3 in close proximity to the crack tip. Differences in minimum measured $p H$ values are due to the different positions of the specific antimony electrode in relation to the crack tip. This fact is based on the experience that the lowest values were found in cases where the crack tip

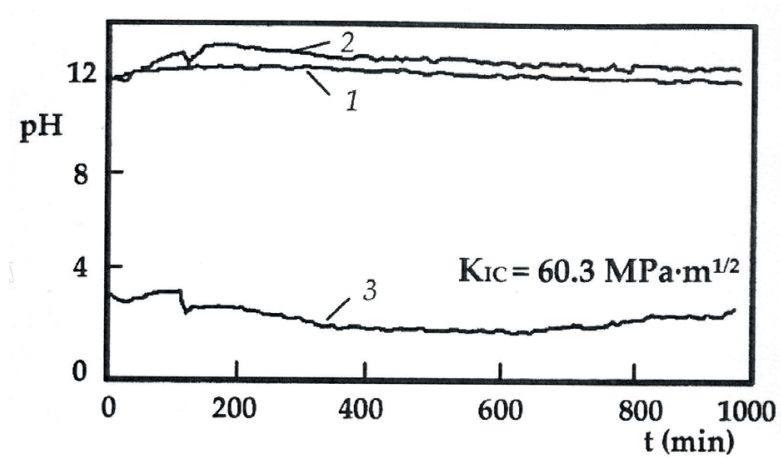

Figure 4 Time flow of measured values of the $\mathrm{pH}$ factor for baseline $\mathrm{pH}=12$

progressed through the location of the scanning position of the antimony electrode, as found by Sojka [12] and Sung et al. [13].

Based on presented results is evident that there is a significant acidification of the solution at the crack tip and the development of atomic hydrogen. This leads in the Mn-Si-Mo steel, optimally heat-treated in terms of the occurrence of irreversible temper embrittlement, to potential embrittlement of the matrix [14].

When the crack is filled with corrosive solution, the iron starts dissolving at its tip. The $\mathrm{Fe}^{2+}$ ions are, in the presence of oxygen, oxidized to $\mathrm{Fe}^{3+}$. In a small crack volume, an increase in the concentration of metal ions occurs, as well as a decrease in the solution $p H$ factor during their hydrolysis. An even more 


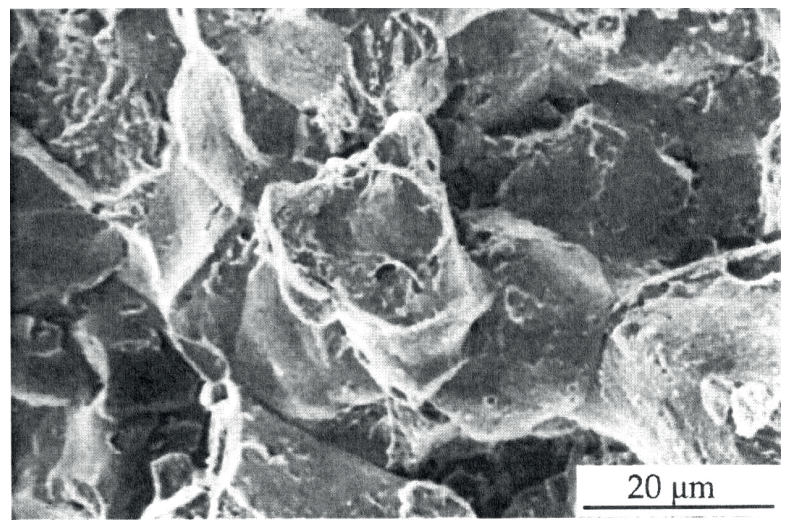

Figure 5 Fracture area of the Mn-Si-Mo steel near the crack tip (intergranular fracture)

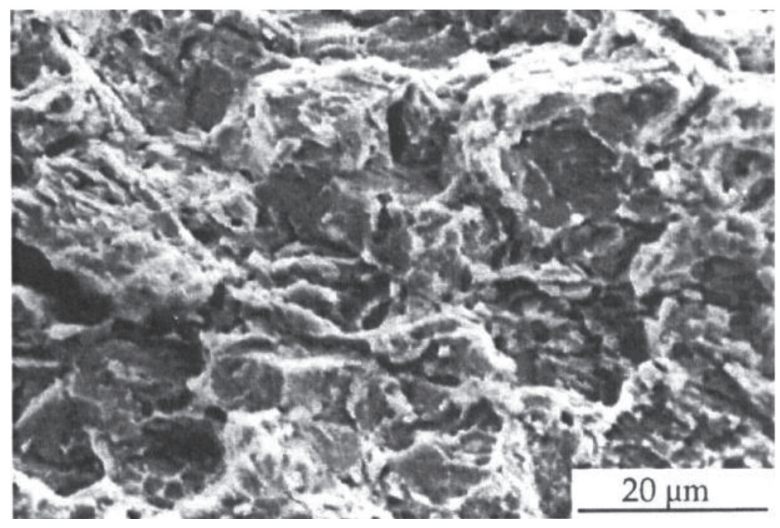

Figure 7 Final fracture area of the Mn-Si-Mo steel (quasi-cleavage character)

significant decrease in the $p H$ factor can be observed probably during the adsorption of $\mathrm{OH}-\mathrm{ions}$ on freshly exposed iron surfaces.

The electrons released by iron oxidation reduce $\mathrm{H}^{+}$ions to atomic hydrogen, which is adsorbed on the surface of the steel and preferably diffuses into the matrix along the grain boundaries of the initial austenite. When the critical concentration of hydrogen in the matrix is reached in front of the crack tip, intergranular decohesion occurs as evident from Figure 5. The intergranular fracture in corrosion cracking tests in aqueous solutions was located in a relatively narrow area just near the front of the fatigue crack.

With the crack development there is an increase in the stress intensity factor at its tip and the acceleration of its propagation. Consequently, in addition to intercrystalline areas, it is possible to observe also quasi-cleavage fracture areas at the fracture surface, see Figure 6 , because the material in front of the crack tip cannot be sufficiently saturated by hydrogen [12].

The further development of the crack leads to an acceleration of its growth, which subsequently leads to a decrease in the effect of hydrogen and, in the event of a final fracture, the occurrence of an intergranular fracture is eliminated. Therefore, the fracture areas are predominantly of a quasi-cleavage character, as shown in Figure 7.

Based on the findings, it can be stated that for the $30 \mathrm{Cr} 2 \mathrm{Ni} 2 \mathrm{Mo}$ steel, the minor content of adsorbed hydrogen,

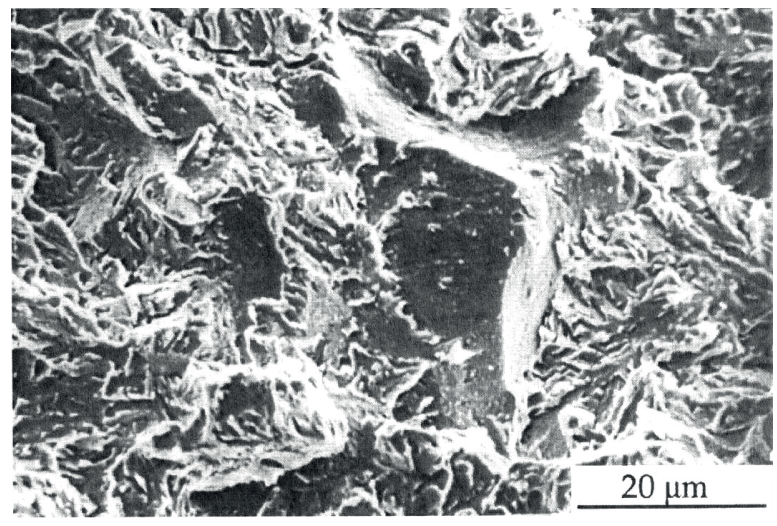

Figure 6 Fracture area of the Mn-Si-Mo steel $2 \mathrm{~mm}$ in front of the crack tip (intergranular fracture with quasi-cleavage areas)

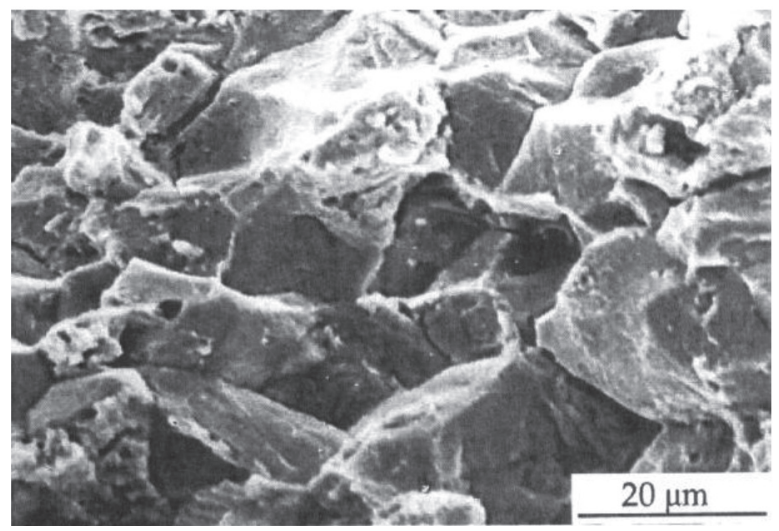

Figure 8 Fracture area of the 30Cr2Ni2Mo steel near the crack tip (intergranular fracture)

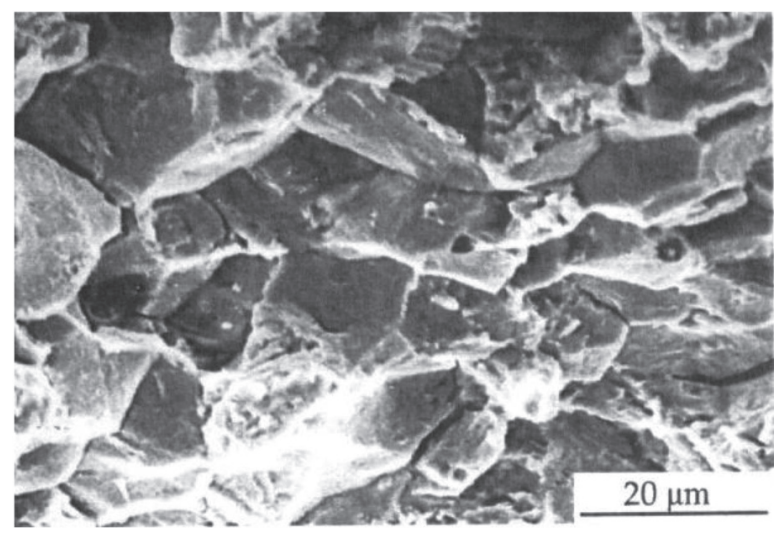

Figure 9 Fracture area of the 30Cr2Ni2Mo steel near the crack tip (intergranular fracture)

diffusing into the matrix to trigger an intergranular cleavage fracture, is sufficient due to the development of the lowtemperature temper embrittlement and the associated "a priori" intergranular decohesion (see Figure 8 and Figure 9), and namely into a significant distance from the fatigue crack tip. It can be stated that the development of temper embrittlement is a significant degradation characteristics of the high-strength steels with the tempered martensite structure. 


\section{Conclusions}

The presented research was focused on the analysis of conditions for development of the stress corrosion cracking of high-strength steels in an aqueous environment with different initial $p H$ factor values. The Mn-Si-Mo and 30Cr2Ni2Mo steels were tested. Data on modification of electrochemical characteristics on the crack tip and in its volume, were obtained following two variants of the heat treatment. The obtained results expand the existing knowledge about localized corrosion processes leading to the refinement of the stress corrosion cracking model when changing the $p H$ factor at the crack tip.

Comparison of susceptibility of the studied steels towards the development of the stress corrosion cracking showed that the susceptibility to this fracture mechanism depends on the heat treatment parameters. In the development of the low-temperature temper embrittlement, the incubation period was significantly shortened and development of the fracture was accelerated, compared to the state of optimized heat treatment where the susceptibility to intergranular fracture was located in close proximity of the fatigue crack tip.

\section{Acknowledgement}

This paper was created at the Faculty of Metallurgy and Materials Engineering, VSB - Technical university of Ostrava as part of the Project No. LO1203 "Regional Materials and Technology Centre-Feasibility Programme" funded by the Ministry Of Education, Youth and Sports of the Czech Republic and the Project SP 2017/58 "Specific Research in the Metallurgical, Materials and Process Engineering."

\section{References}

[1] LYNCH, S. P.: RAJA, V., SHOJI, T. (Eds.): Stress Corrosion Cracking: Theory and Practice. Woodhead Pub., Philadelphia, USA, 90-129, 2011.

[2] DJUKIC, M. B., SIJACKI ZERAVCIC, V., BAKIC, G., SEDMAK, A., RAJICIC, B.: Hydrogen Embrittlement of Low Carbon Structural Steel. Procedia Materials Science, 3, 1167-1172, 2014. https://doi.org/10.1016/j.mspro.2014.06.190

[3] SHIPILOV, S. A.: Mechanisms for corrosion fatigue crack propagation. Fatigue and Fracture of Engineering Materials and Structures, 25(3), 243-259, 2002. https://doi.org/10.1046/j.1460-2695.2002.00447.x

[4] HIRTH, J. P.: Effects of Hydrogen on the Properties of Iron and Steel. Metallurgical Transactions A, 11(6), 861-890, 1980. https:// doi.org/10.1007/BF02654700

[5] ARAFIN, M. A., SZPUNAR, J. A.: A New Understanding of Intergranular Stress Corrosion Cracking Resistance of Pipeline Steel through Grain Boundary Character and Crystallographic Texture Studies. Corrosion Science, 51(1), 119-128, 2009. https://doi. org/10.1016/j.corsci.2008.10.006

[6] ZHANG, G. A., CHENG, Y. F.: Micro-Electrochemical Characterization of Corrosion of Pre-Cracked X70 Pipeline Steel in a Concentrated Carbonate/Bicarbonate Solution. Corrosion Science, 52(3), 960-968, 2010. https://doi.org/10.1016/j. corsci.2009.11.019

[7] PARKINS, R. N., BEAVERS, J. A.: Some Effects of Strain Rate on the Transgranular Stress Corrosion Cracking of Ferritic Steels in Dilute Near-Neutral-pH Solutions. Corrosions 59(3), 258-273, 2003. https://doi org/10.5006/1.3277559

[8] WANG, J. Q., ATTRENS, A.: Microstructure and Grain Boundary Microanalysis of X70 Pipeline Steel. Journal of Materials Science, 38(2), 323-330, 2003. https://doi.org/10.1023/A:1021169700779

[9] BUENO, A. H. S., MOREIRA, E. D., GOMES, J. A. C. P.: Evaluation of Stress Corrosion Cracking and Hydrogen Embrittlement in an API Grade Steel. Engineering Failure Analysis, 36, 423-431, 2014. https://doi.org/10.1016/j.engfailanal.2013.11.012

[10] LI, M. C., CHENG, Y. F.: Mechanistic Investigation of Hydrogen-Enhanced Anodic Dissolution of X-70 Pipe Steel and its Implication on Near-Neutral pH SCC of Pipelines. Electrochimica Acta, 52(28), 8111-8117, 2007. https://doi.org/10.1016/j. electacta.2007.07.015

[11] KANGA, Y., CHEN, W., KANIA, R., VAN BOVEN, G., WORTHINGHAM, R.: Simulation of Crack Growth during Hydrostatic Testing of Pipeline Steel in Near-Neutral pH Environment. Corrosion Science, 53(3), 968-975, 2011. https://doi.org/10.1016/j. corsci.2010.11.029

[12] SOJKA, J.: Resistance of Steels to Hydrogen Embrittlement. VSB-TU Ostrava, Faculty of Metallurgy and Materials Engineering, Ostrava, Czech Republic, 108, 2007.

[13] SUNG, J. K., HWAN, G. J., KYOO, Y. K.: Effect of Post-Weld Heat Treatment on Hydrogen-Assisted Cracking Behavior of High-Strength Process Pipe Steel in a Sour Environment. Scripta Materialia, 67, 895-898, 2012. https://doi.org/10.1016/j. scriptamat.2012.08.021

[14] LYNCH, S. P.: MOODY, N. R. (Ed.): Hydrogen Effects on Material Behavior and Corrosion Deformation Interactions. TMS, Warendale, PA, 449-466, 2003. 